occlusion and revascularisation surgery but that the main component of this delay is not the transfer time between hospitals. Factors that delayed transfer to the surgical unit included attempts to redilate the occlusive lesion in the catheterisation laboratory, the wait for an ambulance to arrive, and the journey time between the hospitals. We believe that these factors would be common to any similar centre in the United Kingdom. The short distance to the surgical centre and the transfer of the patient directly to the cardiac operating theatre, however, may facilitate a more rapid transfer than would be possible in other centres-for example, in places where traffic is congested and surgical cover has not been arranged before angioplasty. Transfer to the surgical centre was usually accomplished within 60 minutes after coronary occlusion, yet the mean delay before revascularisation was 268 minutes (range 180 to 390 minutes). The delay for complicated procedures performed within the Royal Victoria Hospital, where on site surgical cover is available, was virtually identical at 273 minutes (range 108 to 420 minutes). Though any delay between acute coronary occlusion and revascularisation surgery is undesirable, these results show that transferring a patient to the surgical centre does not necessarily increase the delay before revascularisation. The main component of the delay in Belfast was the wait for a cardiac operating theatre to become free. This is probably true for many other centres in the United Kingdom where cardiac surgeons, faced with lengthy waiting lists, continue with their normal surgical caseload while angioplasty is being carried out.

If the recommendations of the task force were adopted and angioplasty programmes abandoned, what would be the implications for management of patients considered suitable for coronary angioplasty? The mortality from coronary angioplasty in the Belfast City Hospital is low at $0.9 \%$ and is comparable with that reported by others. ${ }^{2}$ If coronary angioplasty were abandoned some 150 patients would be added to the waiting list for surgical revascularisation in Northern Ireland each year. As the current waiting list is of the order of 800 patients, a delay of two or more years often occurs before revascularisation surgery is performed. Patients waiting for surgery remain at risk of cardiac events such as myocardial infarction and even death. Studies in patients with symptoms have shown that if only one of the three major coronary arteries has a lesion of $>50 \%$ severity the annual mortality will be approximately $2 \%,{ }^{3}$ particularly when the proximal left anterior descending artery is diseased. ${ }^{+}$This was the commonest lesion in our series. Adding to this the mortality from the surgical procedure itself $(2 \cdot 4 \%$ in the 8991 patients of the coronary artery surgery study registry ${ }^{5}$ ), an increase rather than a decrease in mortality will result from discontinuing procedures simply because facilities for immediate on site surgery are not available.

If angioplasty is performed in a hospital without on site surgical facilities careful selection of cases is required to exclude patients who are at high risk of serious haemodynamic consequences in the event of acute coronary occlusion. If patients do not fall into this high risk group we believe that it is safe to perform angioplasty in a centre without on site surgical cover, provided that this is available at a nearby centre. In the event of coronary occlusion patients who require revascularisation surgery (about one third in our series) can be safely transferred to the surgical unit.

We thank Mr H O'Kane (consultant cardiac surgeon) and Dr M Khan (consultant cardiologist) at the Royal Victoria Hospital for their help in gathering the data.

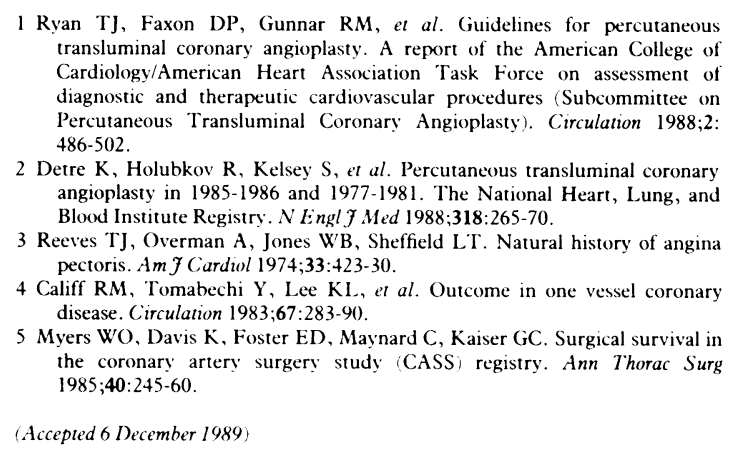

I Ryan TJ, Faxon DP, Gunnar RM, et al. Guidelines for percutaneous transluminal coronary angioplasty. A report of the American College of Cardiology/American Heart Association Task Force on assessment of diagnostic and therapeutic cardiovascular procedures (Subcommittee on Percutaneous Transluminal Coronary Angioplasty). Circulation 1988;2. 486-502.

2 Detre K, Holubkov R, Kelsey S, et al. Percutaneous transluminal coronary angioplasty in 1985-1986 and 1977-1981. The National Heart, Lung, and Blood Institute Registry. N Engl f Med 1988;318:265-70.

3 Reeves TJ, Overman A, Jones WB, Sheffield LT. Natural history of angina pectoris. Am f Cardiol 1974;33:423-30.

4 Califf RM, Tomabechi Y, Lee KL, et al. Outcome in one vessel coronary disease. Circulation 1983;67:283-90.

5 Myers WO, Davis K, Foster ED, Maynard C, Kaiser GC. Surgical survival in the coronary artery surgery study CASS) registry. Ann Thorac Surg $1985 ; 40: 245-60$.

(Accepted 6 December 1989

Department of Thoracic Medicine, Brompton

Hospital, London SW3 6HP

$\mathrm{M}$ W Elliott, $\mathrm{MRCP}$, research fellow

M H Steven, MCSP, senior physiotherapist

G D Phillips, MRCP, senior registrar

M A Branthwaite, FRCP, consultant

Correspondence to: $\mathrm{Dr}$ Branthwaite.

BrMed f 1990;300:358-60

\title{
Non-invasive mechanical ventilation for acute respiratory failure
}

\author{
M W Elliott, M H Steven, G D Phillips, M A Branthwaite
}

\begin{abstract}
The value of mechanical ventilation using intermittent positive pressure ventilation delivered noninvasively by nasal mask was assessed in six patients with life threatening exacerbations of chronic respiratory disease. Median (range) arterial oxygen and carbon dioxide tensions were $4.4(3.5-7.2) \mathrm{kPa}$ and $8.7(5.5-10.9) \mathrm{kPa}$ respectively, with four patients breathing air and two controlled concentrations of oxygen. The arterial oxygen tension increased with mechanical ventilation to a median (range) of 8.7 $(8 \cdot 0-12 \cdot 6) \mathrm{kPa}$ and the carbon dioxide tension fell to $8 \cdot 2(6 \cdot 5-9 \cdot 2) \mathrm{kPa}$. Four patients discharged after a median of 10 (8-17) days in hospital were well five to 22 months later. One died at four days of worsening sputum retention and another after five weeks using the ventilator for 12-16 hours each day while awaiting heart-lung transplantation.

This technique of mechanical ventilation avoids endotracheal intubation and can be used intermittently. Hypercapnic respiratory failure can be relieved in patients with either restrictive or
\end{abstract}

obstructive lung disease in whom controlled oxygen treatment results in unacceptable hypercapnia. Respiratory assistance can be tailored to individual need and undertaken without conventional intensive care facilities.

\section{Introduction}

Intermittent positive pressure ventilation delivered non-invasively through a well fitting nasal mask can control nocturnal hypoventilation and relieve chronic respiratory failure. ${ }^{12}$ The ventilator delivers a predetermined tidal volume either in response to the initiation of a spontaneous breath by the patient or automatically. The concept has developed from the widely used technique of nasal continuous positive airway pressure ${ }^{3}$ in which patients are breathing spontaneously. By contrast, gas flow in and out of the lungs during nasal intermittent positive pressure ventilation depends primarily on the ventilator. We report the use of nasal intermittent positive pressure ventilation in six patients with acute, life 
threatening exacerbations of respiratory disease. Five were managed in a medical ward and one in an intensive care unit.

\section{Patients and methods}

The table lists the clinical details of the six patients. All patients were confused or obtunded, and severely hypoxic and hypercapnic, with peripheral oedema, raised jugular venous pressure, and additional cardiac sounds. The condition of three patients (cases 1-3) had deteriorated acutely as the result of an infection. The condition of two others (cases 4 and 5) had deteriorated over some weeks despite conventional medical treatment. The last patient (case 6) presented with a four month history of worsening breathlessness, ankle swelling, and sleep disturbance, with episodes of loss of consciousness culminating in a transient hemiplegia which resulted in admission to hospital. Two patients (cases 2 and 5 ) were already breathing oxygen enriched air and two more (cases 1 and 3) were known to be chronically hypercapnic and intolerant of oxygen. The unexpectedly low carbon dioxide tension at presentation in one of the patients (case 1) was attributed to the coincident presence of circulatory failure and severe metabolic acidosis. One patient (case 4) developed unacceptable hypercapnia when given oxygen, and one (case 6 ) became almost unrousable.

Nasal intermittent positive pressure ventilation was established using a Respironics nasal mask (available from Medicaid, Bognor Regis) and either a Lifecare PLV 100 (Medicaid) (one patient) or Brompton Pneupac ventilator (Pneupac, Luton) (five patients). Oxygen at a flow rate of $1-2 \mathrm{l} / \mathrm{min}$ was added through a port on the nasal mask. Tidal volumes up to twice those likely during conventional mechanical ventilation (median $1 \cdot 25$ (range $0 \cdot 8-1 \cdot 5$ ) litres) were needed to compensate for leaks around the mask or through the mouth and for the additional dead space of the upper airway. Close supervision was required at first to ensure that the mask was not displaced by restless movements and that the mouth remained sufficiently closed to prevent excessive loss of air. A chin strap was needed to achieve this in all but one patient. Mechanical ventilation was continued for between 12 and 22 hours a day in all subjects, depending on the improvement in symptoms and arterial blood gas tensions, and was used at least overnight until within 24-36 hours of discharge.

\section{Results}

Nasal intermittent positive pressure ventilation was established without difficulty in all patients, and the condition of all of them improved initially (see table). The median (range) arterial oxygen tension increased from $4 \cdot 4(3 \cdot 5-7 \cdot 2) \mathrm{kPa}$ to $8 \cdot 7(8 \cdot 0-12 \cdot 6) \mathrm{kPa}$ with the onset of mechanical ventilation. The corresponding change in arterial carbon dioxide tension was from 8.7 $(5 \cdot 5-10 \cdot 9)$ to $8 \cdot 2(6 \cdot 5-9 \cdot 2) \mathrm{kPa}$. The symptoms of five patients improved with relief of dyspnoea and return to a normal level of consciousness within 12 to 24 hours. This was followed by a rapid diuresis resulting in weight loss of from $4 \mathrm{~kg}$ to $7 \mathrm{~kg}$ without additional diuretic treatment. The condition of the remaining patient improved initially but he developed worsening sputum retention after 24 hours. He declined endotracheal intubation and conventional ventilation and died three days later, with little or no control of blood gas tensions but apparent symptomatic relief of dyspnoea throughout the illness.

Four patients were discharged home after a median hospital stay of 10 days (range 8-17) and were alive and in good health five to 22 months later. Their median (range) arterial oxygen and carbon dioxide tensions recorded while breathing air spontaneously during convalescence, several hours after the last period of assisted ventilation were $8 \cdot 2(7 \cdot 1-9 \cdot 1) \mathrm{kPa}$ and $7 \cdot 1$ $(6 \cdot 1-8 \cdot 2) \mathrm{kPa}$ respectively. One patient (case 6$) \mathrm{con}$ tinued to use nasal intermittent positive pressure during sleep at home and three (cases 1, 2, and 4) used protriptyline to control nocturnal hypoventilation. ${ }^{4}$ One patient (case 5) remained in hospital awaiting heart-lung transplantation, using the ventilator for between 12 and 16 hours a day for the symptomatic relief of dyspnoea, but donor organs did not become available and he died five weeks later.

\section{Discussion}

There is an appreciable mortality among patients with chronic lung disease who require intubation and admission to an intensive care unit, and the incidence of complications is high. They are often difficult to wean from the ventilator and require a prolonged stay in hospital. ${ }^{5}$ Non-invasive ventilation avoids the complications of intubation, permits early mobilisation, adequate nutrition, and the maintenance of morale, and, as in case 3, enables the patient to participate in discussions about future management. Admission to an intensive care unit can often be avoided, although close supervision by an experienced observer is necessary at the outset.

Disadvantages of the technique are that there is no protection of the airway and no direct access to the trachea for suction. Inadequate sputum clearance contributed to one death, but relief of respiratory muscle fatigue and the improved level of consciousness that accompanied rest and correction of abnormalities in blood gas tensions in the others promoted an effective cough and cooperation with physiotherapy.

Correction of abnormalities in arterial blood gas tensions was almost certainly less complete and slower than might have been feasible had these patients been intubated and ventilated conventionally. This slower change in blood gas state and avoidance of sedation may explain why hypotension was not seen when mechanical ventilation was established. Controlling hypercapnia proved considerably more difficult than relieving hypoxaemia, but satisfactory oxygenation could be achieved in all patients without unacceptable hypercapnia, whereas this was impossible while they

Clinical details of six patients treated with nasal intermittent positive pressure ventilation

\begin{tabular}{|c|c|c|c|c|c|c|c|c|c|c|c|c|c|}
\hline \multirow{3}{*}{$\begin{array}{l}\text { Case } \\
\text { No }\end{array}$} & \multirow{3}{*}{$\begin{array}{c}\text { Age } \\
\text { and sex }\end{array}$} & \multirow[b]{3}{*}{ Diagnosis } & \multicolumn{4}{|c|}{ At presentation } & \multirow{2}{*}{\multicolumn{2}{|c|}{ On ventilator }} & \multirow{2}{*}{\multicolumn{2}{|c|}{ During convalescence* }} & \multirow{3}{*}{$\begin{array}{l}\text { Duration of } \\
\text { stay days }\end{array}$} & \multirow[b]{3}{*}{ Outcome } & \multirow{3}{*}{$\begin{array}{c}. \\
\text { Duration o } \\
\text { follow up }\end{array}$} \\
\hline & & & \multicolumn{2}{|c|}{$\mathrm{PaO}_{2} \mathrm{kPa}$} & \multicolumn{2}{|c|}{$\mathrm{PaCO}_{2}(\mathrm{kPa}$} & & & & & & & \\
\hline & & & With air & With oxygen & With air & With oxygen & $\mathrm{PaO}_{2}(\mathrm{kPa})$ & $\mathrm{PaCO}_{2}(\mathrm{kPa}$ & $P a O_{2}\left(h P_{i t}\right)$ & 1) $\mathrm{PiCO}_{2}(\mathrm{kPa})$ & & & \\
\hline 1 & $58 \mathrm{M}$ & Fibrothorax, healed empyema, pneumonia & 3.5 & $5 \cdot 4$ & $5 \cdot 5$ & $4 \cdot 4 \dagger$ & $8 \cdot 7$ & 6.5 & $8 \cdot 3$ & $6 \cdot 2$ & 8 & Well & 5 Months \\
\hline 2 & $61 \mathrm{~F}$ & $\begin{array}{l}\text { Chronic obstructive pulmonary disease, respiratory tract } \\
\text { infection }\end{array}$ & & $7 \cdot 2$ & & $8.8 \neq$ & $8 \cdot 0$ & $8 \cdot 0$ & $9 \cdot 1$ & $6 \cdot 1$ & 8 & Well & 22 Months \\
\hline 3 & $68 \mathrm{M}$ & $\begin{array}{l}\text { Chronic obstructive pulmonary disease, healed tuberculous } \\
\text { empvema, respiratory tract infection }\end{array}$ & $+\cdot 3$ & & 8.5 & & $10 \cdot 3$ & $8 \cdot 2$ & & & 3 & Died & \\
\hline 4 & $48 \mathrm{~F}$ & Chronic obstructive pulmonary disease & 3.5 & 6.4 & 8.4 & $10 \cdot 0 \dagger$ & 8.7 & $8 \cdot 2$ & $7 \cdot 1$ & $8 \cdot 2$ & 17 & Well & 5 Months \\
\hline 5 & $25 \mathrm{M}$ & Cystic fibrosis & & $4 \cdot 5$ & & $10 \cdot 9+$ & $8 \cdot 7$ & $9 \cdot 2$ & 6.6 & $8.5 \dagger$ & 35 & Died & 5 Weeks \\
\hline 6 & $27 \mathrm{M}$ & Kyphoscoliosis & $4 \cdot 6$ & 5 & $10 \cdot 0$ & 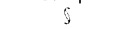 & 12.6 & $8 \cdot 3$ & $8 \cdot 0$ & 8.1 & 10 & Well & 8 Months \\
\hline
\end{tabular}


breathed spontaneously. The carbon dioxide tension rose with the onset of mechanical ventilation from 5.5 to $6.5 \mathrm{kPa}$ in the most severely hypoxic patient (case 1). This man was known to be chronically hypercapnic. The ventilation of such patients is driven by the severity of hypoxaemia and circulatory failure when they are nearing death and so the carbon dioxide tension falls but rises once more if recovery can be secured.

Endotracheal intubation and mechanical ventilation remain the preferred treatment in most cases of severe acute respiratory failure, especially if other systems are deranged at the same time. Continuous positive airway pressure provides relief of dyspnoea and an improvement in oxygenation in a proportion of patients, particularly those in whom hypoxaemia exists without hypercapnia. ${ }^{6}$ Nasal intermittent positive pressure ventilation is feasible in patients with acute on chronic respiratory failure characterised by both hypoxaemia and hypercapnia in whom intubation is considered in- appropriate, difficulties with weaning are anticipated, or long term ventilatory support might be needed. Admission to an intensive care unit can be avoided in some instances at least, and, if intubation does prove necessary, the technique may be useful as a means of helping the return of spontaneous breathing.

1 Ellis ER, Bve P'TB, Bruderer JW, Sullivan CE. Treatment of respiratory failure during sleep in patients with neuromuscular disease. Am Rev Respir Dis 1987; 135:148-52.

2 Carroll N, Branthwaite MA. Control of nocturnal hypoventilation by nasal intermittent positive pressure ventilation. Thorax 1988;43:349-53.

3 Sullivan CE, Berthon-Jones M, Issa FG, Eves L. Reversal of obstructive sleep apnoca by continuous positive airway pressure applied through the nares. Lancet 1981;i:862-5.

4 Simonds AK, Parker RA, Sawicka EH, Branthwaite MA. Protriptyline for nocturnal hypoventilation in restrictive chest wall disease. Thorax 1986;41 $586-90$.

Searle JF. The outcome of mechanical ventilation: report of a five vear study Ann R Coll Surg Engl 1985;67:187-9.

6 Kesten S, Rebuck AS. Nasal continuous positive airway pressure in Pneumocystis carinii pneumonia. Lancet 1988;ii:1414-5.

Accepted 14 November 1989)

\title{
Sleepwalking, night terrors, and consciousness
}

\author{
A H Crisp, B M Matthews, Margaret Oakey, Marion Crutchfield
}

\section{Abstract}

Objective-To determine some personality and psychoneurotic characteristics of adults who have the sleepwalking-night terrors syndrome.

Design-Prospective assessment of two groups of consecutive patients with a firm diagnosis of either of two specific sleep disorders as established clinically and by polysomnography.

Setting-Outpatient sleep disorders clinic and sleep laboratory in a tertiary referral centre.

Patients-12 Patients referred consecutively to the clinic in whom a diagnosis of sleepwalking (six) or night terrors (six) was confirmed.

Main outcome measures-Psychological characteristics as measured at the time of clinical assessment by means of the Eysenck personality questionnaire, the hostility and direction of hostility questionnaire, and the Crown-Crisp experiential index.

Results - Both groups scored exceptionally highly on the hysteria scale of the Crown-Crisp experiential index and the night terrors group also scored highly on the anxiety scale. The patients with sleepwalking also scored highly on a measure of externally directed hostility.

Conclusions-The physiological and psychological features identified in these patients, possibly reflecting different expressions of a constitutional cerebral characteristic, may be explored in terms of hysterical dissociation. The findings contribute to the debate concerning the nature of sleepwalking, in particular with and without the forensic aspects.

\section{Laboratory, Academic} Department of Psychiatry, St George's Hospital Medical School, London SW17 ORE

A H Crisp, FRCPSYCH, professor of psychiatry

B M Matthews, MRCPSYCH, research fellow

Margaret Oakey, BSC, research assistant Marion Crutchfield, $\mathrm{BSC}$, sleep laboratory manager

Correspondence to: Professor Crisp.

\section{Introduction}

The popular notion of sleepwalking is of a trancelike state. The subject usually has open eyes, a blank expression, awareness of but indifference to the environment, and sometimes clumsiness. He or she may waken "fully" before returning to bed and to sleep. There is subsequent amnesia for the event. The term itself implies that walking occurs within sleep. But the question remains: Is the person asleep, awake, conscious, or in some other state of mind? This has special relevance when there is violence with forensic consequences and the issue of responsibility for the act. ${ }^{1.3}$ Controversy continues over whether the disorder is akin to functionally generated hysterical fugue states, underwritten by a process of dissociation within wakefulness, ${ }^{4+6}$ or whether it is an automatism precipitated by an abnormal sleep process and unrelated to the processes of the waking mind. Dissociation is defined as a defect of mental integration whereby one or more groups of mental processes become separated off from normal consciousness and, thus separated, function as a whole.

Kales et al, ${ }^{\times}$Broughton," and Fisher et al ${ }^{\prime \prime \prime}$ agreed that both sleepwalking and night terrors typically erupt out of stage 4, non-rapid eye movement (deep) sleep. Kales et al identified subsequent persistence of slow waves for a short while, which they suggested might reflect brain immaturity. ${ }^{x}$ They postulated the relevance of both organic and functional factors. Broughton, reporting in English on his earlier work with Gastaut, found the episodes to be associated with high amplitude $\alpha$ rhythm, similar to that prompted in normal subjects wakened from deep sleep, and he considered the patients to be suffering from a disorder of arousal." Fisher et al reported similar findings in the electroencephalogram and concluded that night terrors arise because of a breach in the subject's ability to control anxiety."

More recently Oswald and Evans have come down emphatically on the side of sleepwalking being exclusively a disorder of sleep. ${ }^{3}$ They described violent behaviour during sleepwalking in three subjects as being out of character and claimed that the subjects behaved automatically during the events and were subsequently amnesic for them.

We contribute to the debate with the following study

Patients attend the sleep disorders clinic for a wide variety of sleep disorders. They are assessed clinically during an initial two to three hour long consultation, during which information is obtained both from them and from witnesses-for example, the spouse. All patients also complete certain psychological tests 